\title{
MicroRNA-221 regulates proliferation of bovine mammary gland epithelial cells by targeting the STAT5a and IRS1 genes
}

\author{
B. L. Jiao, ${ }^{1}$ X. L. Zhang, ${ }^{1}$ S. H. Wang, ${ }^{1}$ L. X. Wang, ${ }^{1}$ Z. X. Luo, ${ }^{1}$ H. B. Zhao ${ }^{2}$ H. Khatib, ${ }^{3}$ and X. Wang ${ }^{1 *}$ \\ ${ }^{1}$ College of Animal Science and Technology, Northwest A\&F University, Yangling, Shaanxi 712100, China \\ ${ }^{2}$ Institute of Animal Science and Veterinary Medicine, Shandong Academy of Agricultural Sciences, Jinan, Shandong 250100, China \\ ${ }^{3}$ Department of Animal Sciences, University of Wisconsin-Madison 53706
}

\section{ABSTRACT}

MicroRNAs (miRNA) play an essential role in mammary gland development and lactation. Previous studies in cattle have shown that miR-221 is highly expressed in peak compared with early lactation. However, the functions of miR-221 in bovine mammary gland epithelial cells and the mechanisms by which this miRNA affects cell proliferation and milk synthesis remain unclear. We hypothesized that miR-221 targets and modulates the expression of specific genes in the Janus kinase-signal transducer and activator of transcription (JAK-STAT) and phosphatidylinositol 3-kinase-proteinkinase B/ mammalian target of rapamycin (PI3K-Akt/mTOR) signaling pathways, which have crucial roles in lactation in cattle. Following transfection of miR-221 into cultured bovine mammary gland epithelial cells, inhibition of cell proliferation and reduced viability of these cells were observed using the 3-(4,5-dimethylthiazol2-yl)-2,5-diphenyltetrazolium bromide (MTT) assay and flow cytometry analysis. To elucidate the molecular mechanisms of the effects of miR-221 on cell proliferation, we selected potential candidate genes that can be targeted by miR-221 using bioinformatics prediction tools. The dual luciferase assay revealed that STAT5a, STAT3, and IRS1 interact with miR-221 by its direct binding to the $3^{\prime}$-untranslated regions (UTR) of these genes. Subsequent analysis showed that transfection of a miR-221 mimic resulted in significantly decreased expression of STAT5a and IRS1 at both the RNA and protein levels using quantitative real-time PCR and Western blot analyses. Furthermore, expression levels of the downstream genes SOCS3, AKT3, and mTOR that are regulated by $S T A T 5 a$ and IRS1 in the JAKSTAT and PI3K-Akt/mTOR signaling pathways, were also altered after miR-221 transfection. This is the first study to reveal the mechanisms by which miR-221 in-

Received May 23, 2018.

Accepted August 24, 2018.

*Corresponding author: wxwza@126.com hibits mammary gland epithelial cell proliferation by targeting STAT5a and IRS1, key genes in the PI3KAkt/mTOR and JAK-STAT signaling pathways.

Key words: miR-221, STAT5a, IRS1, bovine mammary gland epithelial cell, cell proliferation

\section{INTRODUCTION}

The mammary gland is a unique organ that can pass through several distinct stages of development, including embryonic, pubertal, pregnancy, lactation, and involution (Macias and Hinck, 2012). Consequently, the tissues of the mammary gland experience cell proliferation, differentiation, and apoptosis cycles during adult life that are under the regulation of distinct hormones, growth factors, and coding genes (Topper and Freeman, 1980; Oka et al., 1991; Liu et al., 1997; Wiseman and Werb, 2002; Shackleton et al., 2006). These stagebased processes require numerous signaling pathways that have distinct regulatory functions (Hennighausen and Robinson, 2001; Robinson, 2004; Howard and Ashworth, 2006). The primary signaling pathways Janus kinase-signal transducer and activator of transcription (JAK-STAT; Watson and Burdon, 1996; Mapes et al., 2017) and phosphatidylinositol 3-kinase-protein kinase B/mammalian target of rapamycin (PI3K-Akt/ mTOR) are essential for mammary gland development and milk protein synthesis (Sobolewska et al., 2009). The STAT $5 a$ gene, a member of the JAK-STAT signaling pathway, plays a pivotal role in the proliferation, secretory differentiation, and survival of mammary epithelial cells (Cui et al., 2004; Yamaji et al., 2009; Furth et al., 2011; Liu et al., 2012b). The PI3K-Akt/mTOR signaling pathway regulates a broad range of cellular processes including survival, cell proliferation, growth, and metabolism (Ersahin et al., 2015). However, the mechanisms by which these pathways are regulated in cattle are poorly understood.

MicroRNAs (miRNA) are small non-coding RNA sequences of 22 to $25 \mathrm{nt}$ that play roles in the regulation of gene expression by binding to the $3^{\prime}$-untranslated 
region (UTR) of target mRNA (Huang et al., 2011). Several studies have reported miRNA involvement in mammary gland development (Silveri et al., 2006; Tanaka et al., 2009; Wang et al., 2018), maintenance of mammary epithelial progenitor cells (Ibarra et al., 2007), outgrowth of epithelial ducts (Ucar et al., 2010), and in proliferation and differentiation of mammary epithelial cells (Li et al., 2010; Howe et al., 2012; Liu et al., 2012a). In addition, mammary gland tissue-specific and developmental stage-specific miRNA have been found in different species including human, mouse, and bovine (Liu et al., 2004; Avril-Sassen et al., 2009; Wang et al., 2012; Phua et al., 2015). For example, expression of miR-205 was found to be associated with an increase in the number of mammary gland stem cells in the mouse by acting on the PTEN gene, and it plays an important role in the regulation of mammary stem cell fate and tumorigenesis (Greene et al., 2010; Chao et al., 2014). Overexpression of miR-101a and miR-126-3p led to inhibition of mammary gland epithelial cell differentiation (Tanaka et al., 2009; Wei et al., 2011). In cattle, miR-15a was found to inhibit mammary gland epithelial cell vitality and lactation by targeting the GHR gene (Li et al., 2012).

Recent studies have reported that miR-221 regulates cell growth and cell cycle progression in various cell types including cancer cells (Galardi et al., 2007; Pineau et al., 2010; Rong et al., 2013; Chu et al., 2018). In cattle, expression of miR-221 was found to be higher in peak lactation than in early lactation (Wang et al., 2012). However, the specific mechanisms by which miR221 affects bovine mammary gland development remain poorly understood. Thus, the objectives of this study were to investigate whether miR-221 affects the proliferation of mammary epithelial cells and to characterize the target genes of miR-221 in the JAK-STAT and PI3K-Akt/mTOR signaling pathways and to evaluate the regulatory effects of miR-221 on these genes.

\section{MATERIALS AND METHODS}

\section{Effects of miR-221 Transfection on Cell Proliferation}

Cell viability and cell cycle analyses were performed to study the effects of miR-221 on cell proliferation. The bovine mammary epithelial cell (BMEC) line was donated by H. B. Zhao's laboratory (Northwest A\&F University, Shaanxi, China). The cell line was transfected with SV40 large T antigen, which confers immortality to BMEC. The cell line is responsive to manipulations both in extracellular matrix and in the presence of lactogenic hormones. When differentiated, the cells synthesize and secrete $\alpha$ - and $\beta$-casein. As such, BMEC cells represent an in vitro model for bovine lactation (Huynh et al., 1991). To determine cell viability, BMEC were cultured in DF-12 growth medium (a 1:1 mixture of Ham's F-12 and Dulbecco's modified Eagle's medium) supplemented with $10 \%$ heat inactivated fetal bovine serum (FBS), and 1\% penicillin streptomycin (all from Gibco, Grand Island, NY) at $37^{\circ} \mathrm{C}$ with $5 \% \mathrm{CO}_{2}$. Single cell pellets were seeded in a 96-well plate at a concentration of $1 \times 10^{4}$ cells per well. For transfections of BMEC, miR-221 mimic, miR-221 inhibitor, and their corresponding negative control oligonucleotides were synthesized by Shanghai GenePharma Co. Ltd. (Shanghai, China). The miR-221 mimic $(40 \mathrm{n} M)$ and miR-221 inhibitor $(80 \mathrm{n} M)$ were transfected into BMEC using Lipofectamine 2000 (Invitrogen, Carlsbad, CA) according the manufacturer's protocol. After transfection for $48 \mathrm{~h}$, the culture medium was aspirated, $50 \mu \mathrm{L}$ of 3-(4,5-dimethylthiazol2-yl)-2,5-diphenyltetrazolium bromide (MTT; $0.5 \mathrm{mg} /$ $\mathrm{mL}$, Sigma, St. Louis, MO) was added to each well, and the culture plates were further incubated for $4 \mathrm{~h}$ in the dark at $37^{\circ} \mathrm{C}$. Then, $150 \mu \mathrm{L}$ of dimethyl sulfoxide (Amersco, Solon, $\mathrm{OH}$ ) was added to each to dissolve the formed formazan crystals. A SynergyH1 multi-detector microplate reader (BioTek, Winooski, VT) was used to measure the absorbance of each well at a wavelength of $570 \mathrm{~nm}$. The relative cell viability was calculated using optical density at $570 \mathrm{~nm}\left(\mathrm{OD}_{570}\right)$ absorbance value ratios.

For cell cycle analysis, single cell pellets were fixed with $70 \%$ ethanol and incubated with PBS supplemented with $50 \mu \mathrm{g} / \mathrm{mL}$ propidium iodide (Abcam, Shanghai, China) and $100 \mu \mathrm{g} / \mathrm{mL}$ RNase A (Beyotime, Beijing, China) at $37^{\circ} \mathrm{C}$ for $30 \mathrm{~min}$. Cell cycle was measured with BD FACSCalibur flow cytometer (Becton Dickinson, San Jose, CA). Data were analyzed using ModFit LT 4.0 software (Becton Dickinson).

\section{Interactions Between miR-221 and Target Genes}

Based on the seed sequence of miR-221 and on their roles in the JAK-STAT and PI3K-Akt/mTOR signaling pathways, mTOR, IRS1, PI3KR1, STAT3, IGF1, STAT5a, PRLR, and AKT3 were considered potential targets of miR-221. To identify the interactions between miR-221 and target genes, the dual luciferase reporter system was used. First, 3'-untranslated region (UTR) fragments of the targets were amplified by PCR and ligated into the psi-CHECK-2 vector (Promega, Madison, WI) using $X h o \mathrm{I}$ and NotI restriction enzymes. Primers used for PCR amplification were synthesized by Invitrogen. All the qPCR experiments were performed according to the MIQE checklist (http://www.rdml.org/miqe .php). The vectors Psicheck-2-mTOR, Psicheck-2-IRS1, Psicheck-2-PI3KR1, Psicheck-2-STAT3, Psicheck- 
Table 1. Real-time (RT) quantitative (q)PCR primer information for microRNA (miR)-221 and target genes

\begin{tabular}{|c|c|c|c|}
\hline Gene & $\begin{array}{l}\text { Accession } \\
\text { number }\end{array}$ & Sequence $\left(5^{\prime}\right.$ to $3^{\prime} ; \mathrm{F}=$ forward, $\mathrm{R}=$ reverse $)$ & $\begin{array}{l}\text { Product } \\
\text { size (bp) }\end{array}$ \\
\hline \multirow[t]{2}{*}{ IRS1 } & \multirow[t]{2}{*}{ XM_003585773 } & F: TTGGTCAAGGACTTCAAACAG & \multirow[t]{2}{*}{227} \\
\hline & & R: TTGCTGAGGTCATTTAGGTCT & \\
\hline \multirow[t]{2}{*}{ STAT3 } & \multirow[t]{2}{*}{ NM_001012671 } & F: AGTGATGAACATGGAAGAGTC & \multirow[t]{2}{*}{156} \\
\hline & & R: TGATACACCTCAGTCTCAAAG & \\
\hline$m T O R$ & XM_002694043 & R: ATGTTCTTCAGGATTTTGTTG & 202 \\
\hline \multirow{2}{*}{ AKT3 } & \multirow{2}{*}{ XM_024975966 } & F: TACCTTATCCCСТCAACAACT & \multirow[t]{2}{*}{211} \\
\hline & & R: АTTCTCTCTTCTTCTTGCCTC & \\
\hline \multirow[t]{2}{*}{$G A P D H$} & \multirow[t]{3}{*}{ NM_001034034 } & F: AGATGGTGAAGGTCGGAGTG & \multirow[t]{2}{*}{189} \\
\hline & & R: CGTTCTCTGCCTTGACTGTG & \\
\hline miR-221 RT primer & & CTCAACTGGTGTCGTGGAGTCGGCAATTCAGTTGAGAAACCCAG & 60 \\
\hline
\end{tabular}

2-IGF1, Psicheck-2-STAT5a, Psicheck-2-PRLR, and Psicheck-2-AKT3 were Sanger sequenced to verify the presence of 3 '-UTR fragments. Then, the dual luciferase reporter system was used to measure the interactions between miR-221 and its targets using HEK293T cells. The cells were cultured in Dulbecco's modified Eagle's medium (Gibco) with $10 \%$ FBS, $100 \mathrm{U} / \mathrm{mL}$ penicillin, and $100 \mu \mathrm{g} / \mathrm{mL}$ streptomycin at $37^{\circ} \mathrm{C}$ with $5 \% \mathrm{CO}_{2}$. The dual luciferase transfection was performed in 24well plates where each well was co-transfected with 300 $\mathrm{ng}$ of dual luciferase reporter vector and $20 \mathrm{pmol}$ of miR-221 mimic or 40 pmol of miR-221 inhibitor with Lipofectamine 2000 for $36 \mathrm{~h}$ (Invitrogen). Transfections were performed in triplicate. To assess the interactions between miR-221 and the potential target genes, the firefly and Renilla luciferase activities were measured using the dual luciferase reporter kit (Promega).

\section{Effects of miR-221 on the Expression of Its Target Genes}

To study the effects of miR-221 on the activity of its target genes, miR-221 mimic or inhibitor were transfected into BMEC as described in the previous section. Cells were collected $48 \mathrm{~h}$ after transfection. The cells were harvested when the confluence reached $90 \%$. All transfections were performed in triplicate. Total RNA was extracted using Trizol (Invitrogen) following the manufacturer's instructions. To test whether miR-221 was taken up by BMEC, cDNA was synthesized using a specific stem-loop RT primer for miR-221 through PrimerScript RT reagent kit with gDNA Eraser (TaKaRa, Dalian, China). Expression of miR-221 was quantified with $U 6$ as an endogenous control using the SYBR Premix Ex TaqTM II kit (TaKaRa) according to the manufacturer's protocol. The miR-221 primers are listed in Table 1, and the U6 primer sequences were synthesized according to Guan et al. (2017). The realtime quantitative (q)PCR reactions consisted of $10 \mu \mathrm{L}$ of SYBR Premix Ex Taq, $0.6 \mu \mathrm{L}$ of miR-221 forward primer $(10 \mu M), 0.6 \mu \mathrm{L}$ of universal reverse primer $(10$ $\mu M), 2 \mu \mathrm{L}$ of miRNA RT product $(100 \mathrm{ng} / \mu \mathrm{L})$, and 6.8 $\mu \mathrm{L}$ of double-distilled $\mathrm{H}_{2} \mathrm{O}$ to a final volume of $20 \mu \mathrm{L}$. The qPCR protocol was initiated with an incubation of 3 min at $95^{\circ} \mathrm{C}$, followed by 40 cycles of $95^{\circ} \mathrm{C}$ for $12 \mathrm{~s}$ and $62^{\circ} \mathrm{C}$ for $40 \mathrm{~s}$ using a Bio-Rad CFX96 Touch Real-time PCR detection system (Bio-Rad, Hercules, CA).

For coding genes, the cDNA was synthesized using PrimerScript RT regent kit with gDNA Eraser (TaKaRa) according to the manufacturer's protocol. Then, the expression levels of the target genes STAT5a, IRS1, STAT3, and the downstream genes SOCS3, AKT3, and $m T O R$ in the JAK-STAT and PI3K-Akt/mTOR signaling pathways were quantified with SYBR Premix Ex Taq kit (TakaRa) using GAPDH as a reference gene. All qPCR reactions were run in triplicate in a $20-\mu \mathrm{L}$ volume. Primers for $\mathrm{qPCR}$ are listed in Table 1 . The initial cycling conditions were $95^{\circ} \mathrm{C}$ for $10 \mathrm{~min}$, followed by 40 cycles of $95^{\circ} \mathrm{C}$ for $12 \mathrm{~s}$ and $58^{\circ} \mathrm{C}$ for $30 \mathrm{~s}$.

\section{Western Blot Analysis of IRS1 and STAT5a}

Genes found to be regulated by miR-221 at the transcriptional level were further analyzed by Western blot. Total protein was extracted from the BMEC using RIPA (radioimmunoprecipitation assay) cell lysis solution (Applygen, Beijing, China) after transfection for $72 \mathrm{~h}$. The samples were separated on a $10 \%$ SDS-PAGE gel (30 $\mu \mathrm{g}$ of protein per sample) and transferred onto nitrocellulose membranes (Bio-Rad, Shanghai, China). 
After blocking with $5 \%$ skim milk powder solution for 1 $\mathrm{h}$ at $37^{\circ} \mathrm{C}$, the membranes were incubated overnight at $4^{\circ} \mathrm{C}$ with a murine polyclonal rabbit antibody against IRS1 and STAT5a (Santa Cruz Biotechnology Inc., Dallas, TX), and then incubated with a horseradish peroxidase (HRP)-conjugated secondary goat-anti-rabbit IgG (Zhongshan-Bio, Beijing, China). The protein bands were visualized with Super ECL Plus (ApplyGEN), and GAPDH (Abcam) was used as an internal reference control.

\section{Data Analysis}

To determine the effect of miR-221 mimic or inhibitor on gene expression, the relative expression of potential target genes was estimated using the $2^{-\Delta \Delta \mathrm{Ct}}$ method (Livak and Schmittgen, 2001). The miR-221 mimic group was compared with the mimic control group, and the miR-221 inhibitor group was compared with the inhibitor control group. To detect interactions between miR-221 and potential target genes, the Renilla/firefly activity was compared between mimic and mimic control group, and between inhibitor and inhibitor group in HEK293T cells. Data were expressed as means \pm standard error of the mean. Statistical analysis was performed using unpaired $t$-test in GraphPad Prism 5.0 software (GraphPad Software, San Diego, CA). Statistical significance was declared as $P<0.05, P<0.01$, and $P<0.001$.

\section{RESULTS}

\section{Functional Analysis of miR-221 Effects on BMEC Proliferation}

To explore the effect on cell proliferation, different concentrations of miR-221 mimic and inhibitor were supplemented to BMEC in 6-well plates and incubated for $48 \mathrm{~h}$. The qPCR analysis revealed that supplementation of $100 \mathrm{pmol} / \mathrm{L}$ miR-221 mimic significantly increased the level of miR-221 in BMEC compared with the mimic-negative control (Figure 1). In contrast, supplementation of $80 \mathrm{pmol} / \mathrm{L}$ inhibitor resulted in a significant decrease of miR-221 level in BMEC compared with other concentrations used (Figure 1).

Proliferation of BMEC was assayed by the MTT assay $48 \mathrm{~h}$ following transfection of miR-221 mimic or inhibitor. Cell viability was significantly reduced in BMEC transfected with miR-221 mimic compared with the control cells $(P<0.001)$, whereas supplementation of miR-221 inhibitor led to a significant increase $(P<$ 0.001 ) in cell viability compared with controls (Figure $2 \mathrm{~A})$.
To further validate the effect of miR-221 on cell proliferation, cell cycle analysis was performed using the flow cytometry method. As shown in Figure 2B, most BMEC were in $\mathrm{G}_{1}$ phase. Figure $2 \mathrm{~B}$ shows that $18.15 \%$ of cells in the miR-221 mimic group were in the DNA post-synthesis phase $\left(\mathrm{G}_{2}\right)$ or synthesis phase (S) compared with $31.27 \%$ of cells in the mimic-control group, representing a cell reduction of 13.12 percentage units in the mimic group. In contrast, cells in the $\mathrm{G}_{2}$ and $\mathrm{S}$ phases were increased by $10.57 \%$ in the miR-221 inhibitor group compared with the inhibitor control group (Figure 2B).

\section{Interactions Between miR-221 and Its Targets}

To better understand the mechanisms by which miR-221 affects cell viability and cell proliferation, we

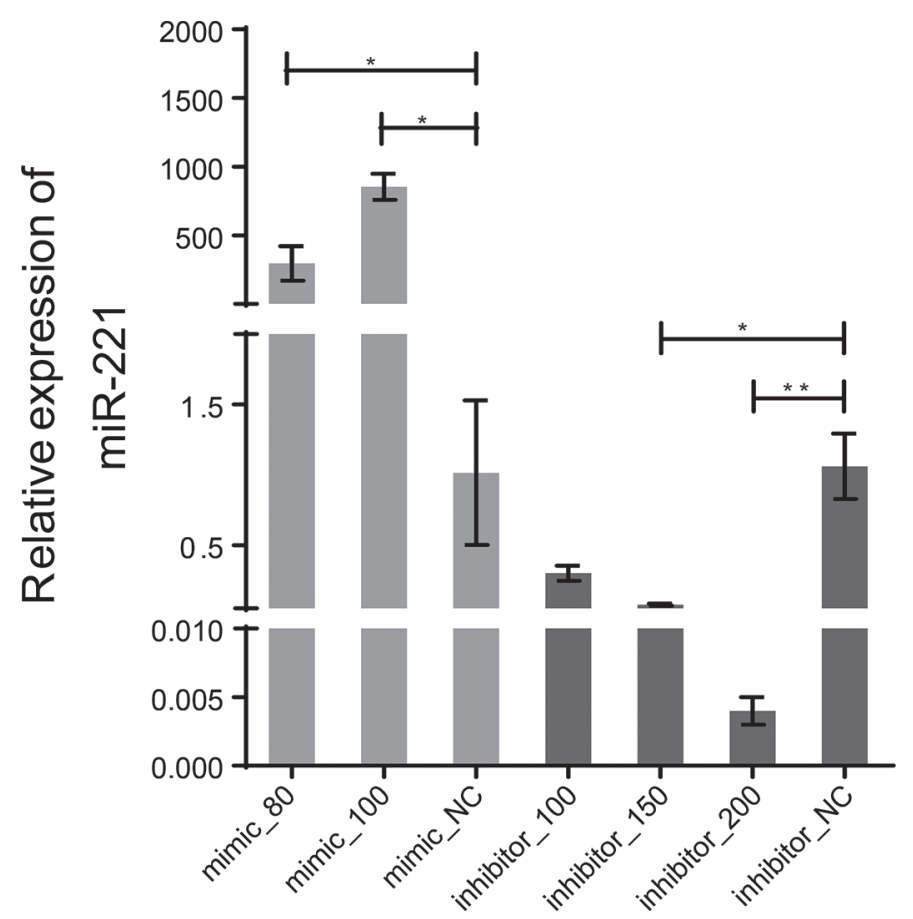

Figure 1. Quantitative real-time PCR of microRNA (miR)-221 following transfection of miR-221 mimic and inhibitor into bovine mammary epithelial cells (BMEC). Transfection with $100 \mathrm{pmol} /$ well of miR-221 mimic led to the highest expression of miR-221 in BMEC compared with the mimic control group. Transfection of $200 \mathrm{pmol}$ of inhibitor/well for $48 \mathrm{~h}$ resulted in a significant decrease in miR-221 expression level in BMEC compared with the nonspecific scrambled control (NC). Data are from 3 independent experiments and presented as mean \pm SEM $(\mathrm{n}=3) ;{ }^{*} P<0.05$ and ${ }^{*} P<0.01$ : significant difference between mimic or inhibitor and respective controls (NC). Mimic_80 and mimic_100 indicate mimic concentrations of 80 and $100 \mathrm{pmol} /$ well, respectively. Inhibitor_100, inhibitor_150, and inhibitor_200 indicate inhibitor concentrations of 100, 150, and $200 \mathrm{pmol} /$ well, respectively. 
tested the activities of genes targeted by miR-221. Target genes of miR-221 were predicted using TargetScan (http://www.targetscan.org/vert_71/) and DNAman software (Lynnon Corp., San Ramon, CA) based on the mature sequence of miR-221 (http://www.mirbase .org). The corresponding psi-check2 vectors were constructed and transferred into HEK293T cells with miR$221 \mathrm{mimic} /$ inhibitor. The Renilla/firefly luciferase assay showed that the activities of mTOR, IRS1, STAT3, IGF1, STAT5a, and PRLR genes were reduced after transfecting miR-221 mimic (Figure 3), whereas the activities of IRS1, STAT3, STAT5a, and AKT3 were increased by transfecting miR-221 inhibitor (Figure 3). The activity of PI3KR1 did not change significantly following miR-221 mimic or inhibitor transfections into HEK293T cells. Thus, the dual luciferase results indicate that miR-221 interacts with IRS1, STAT5a, and STAT3 genes by binding to their 3 '-UTR. Therefore, these genes were selected for further analysis to study their expression activities in BMEC following miR-221 binding.

\section{MiR-221 Regulates the Expression of STAT5a and IRS1}

To investigate the potential regulatory role of miR221 on IRS1, STAT5a, and STAT3 genes, miR-221 mimic and inhibitor were transfected into the cultured BMEC. Figure 4 shows the expression levels of IRS1, STAT5a, and STAT3 following transfection of miR-221 mimic and its inhibitor. Overexpression of miR-221 in BMEC was associated with a decrease in $\operatorname{IRS1}(P<$ $0.05)$ and STAT5a $(P<0.001)$ expression levels (Figure $4 \mathrm{~A})$, whereas supplementation of miR-221 inhibitor led to increased expression of IRS1 $(P<0.01)$ and STAT5a $(P<0.05 ;$ Figure 4A). Although STAT3 showed similar trends of expression to those of IRS1 and STAT5a, the difference compared with control cells was not statistically significant.

To test whether IRS1 and STAT5a are regulated by miR-221 at the protein level, a Western blot was performed (Figure 4B). Transfection of miR-221 mimic into BMEC led to reduced expression of IRS1 $(P<$

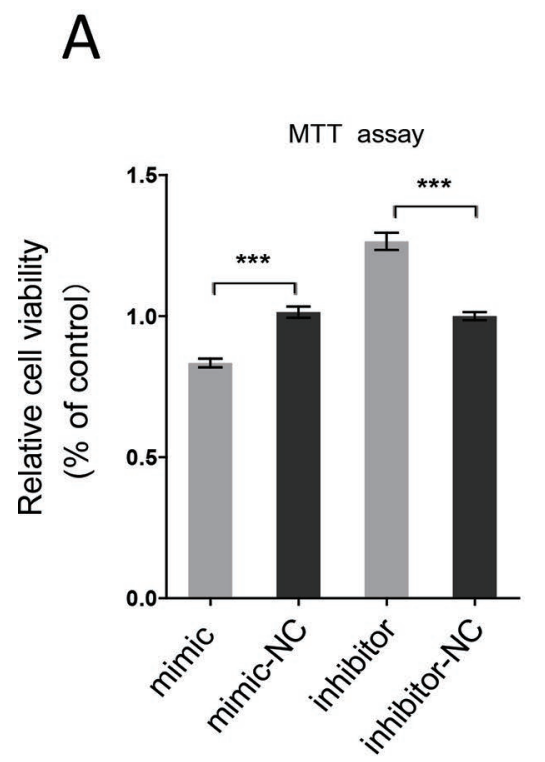

\section{B}
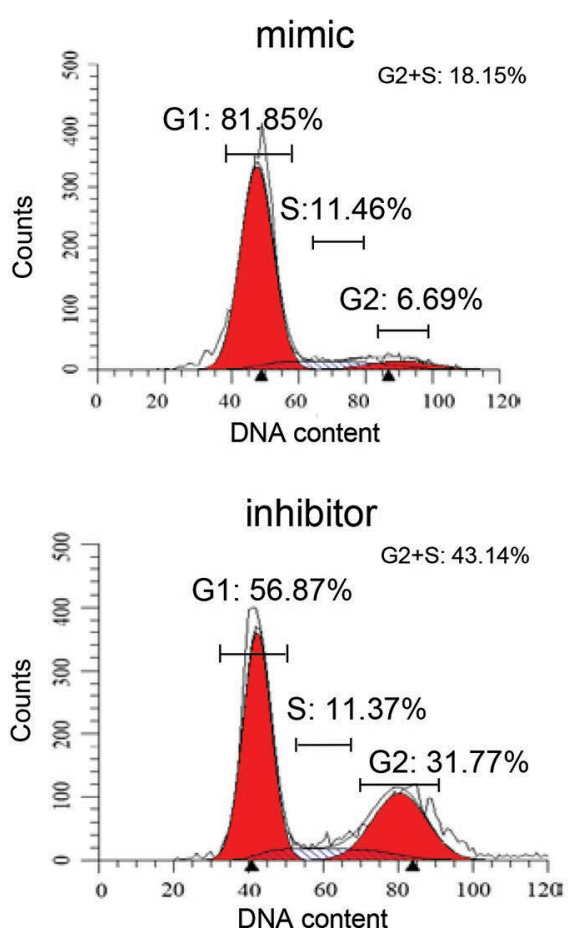
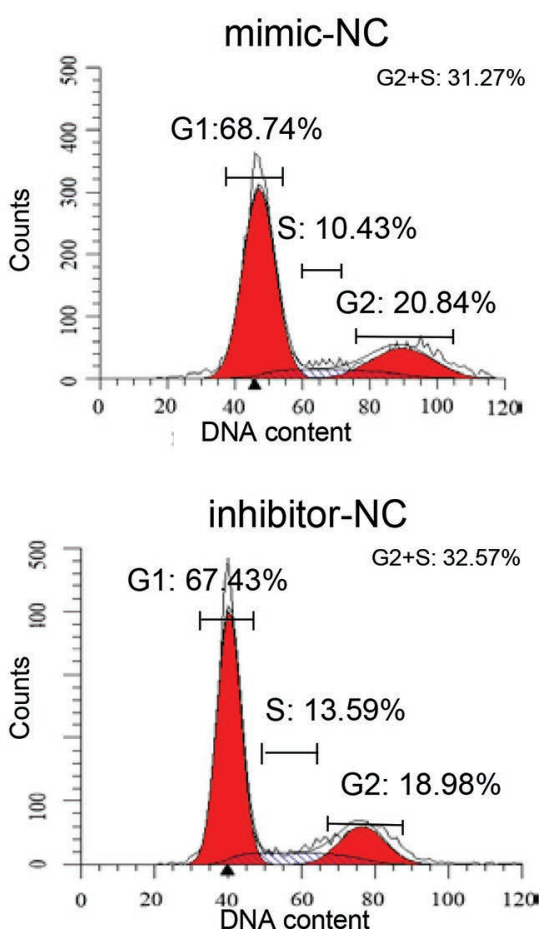

Figure 2. Cell viability and proliferation assays of bovine mammary epithelial cells (BMEC) transfected with microRNA (miR)-221. (A) Transfection of miR-221 mimic and miR-221 inhibitor resulted in a decrease and increase, respectively, in the activity of BMEC using the 3-(4,5-dimethylthiazol-2-yl)-2,5-diphenyltetrazolium bromide (MTT) assay; (B) cell proliferation analysis using flow cytometry showed that miR-221 mimic-transfected BMEC in the $\mathrm{G}_{2}$ and $\mathrm{S}$ phases were reduced by 13.12 percentage units compared with the control group, whereas cells transfected with miR-221 inhibitor were increased by 10.57 percentage units in the $\mathrm{G}_{2}$ and $\mathrm{S}$ phases compared with the inhibitor control. The data were derived from 3 independent experiments on different days and are presented as mean \pm SEM $(\mathrm{n}=3)$. $* * * P<0.001$ : significant difference between mimic or inhibitor and respective controls (NC). 
$0.01)$ and STAT5a $(P<0.001)$ proteins (Figure $4 \mathrm{C})$, whereas expression levels of these proteins were increased in BMEC transfected with miR-221 inhibitor (Figure 4C).

\section{Expression of Downstream Genes in the JAK-STAT and PI3K-Akt/mTOR Signaling Pathways}

A previous study reported that overexpression of SOCS3 in bovine mammary epithelial cells significantly inhibited cell growth and viability and that SOCS3 could be targeted by STAT5a, a member of the JAK-STAT signaling pathway (Huang et al., 2013). The AKT3 and $m T O R$ genes are located in thePI3K-Akt/mTOR signaling pathway, which is activated by phosphorylation of IRS1 (Law et al., 2016). Therefore, the expression of SOCS3, AKT3, and mTOR was assessed in BMEC by qPCR following miR-221 transfection. Figure 5 shows that overexpression of miR-221 significantly decreased the expression of SOCS3, AKT3, and mTOR genes, whereas supplementation of miR-221 inhibitor resulted in increased expression of SOCS3 and mTOR compared with control cells. The expression of AKT3 was also increased after miR-221 inhibitor transfection but not significantly compared with controls.

\section{DISCUSSION}

Previous studies have shown that miR-221 plays roles in disease, cell differentiation, and cell proliferation processes (Felli et al., 2005; Chen et al., 2018), mammary gland tumorigenesis (Lv et al., 2017), and milk production traits (Wang et al., 2018) . Furthermore, miR-221 has been found to be highly expressed in early lactation compared with fresh and dry periods, suggesting a role in the control of endothelial cell growth and proliferation (Wang et al., 2012). Thus, the objective of this study was to elucidate the molecular mechanisms by which miR-221 affect mammary gland development. The results of the MTT and flow cytometry assays revealed that overexpression of miR-221 in cultured BMEC decreased cell viability and inhibited cell proliferation.

Given the roles of the JAK-STAT and PI3K-Akt/ mTOR signaling pathways in mammary gland development and lactation, we sought to test whether genes in these pathways are potential targets of miR-221 binding. Indeed, using the dual luciferase assay in HEK293T cells, we found that miR-221 interacts with the $3^{\prime}$-UTR of STAT5a, STAT3 (members of the JAK-STAT pathway), and IRS1 (a member of the PI3K-Akt/mTOR
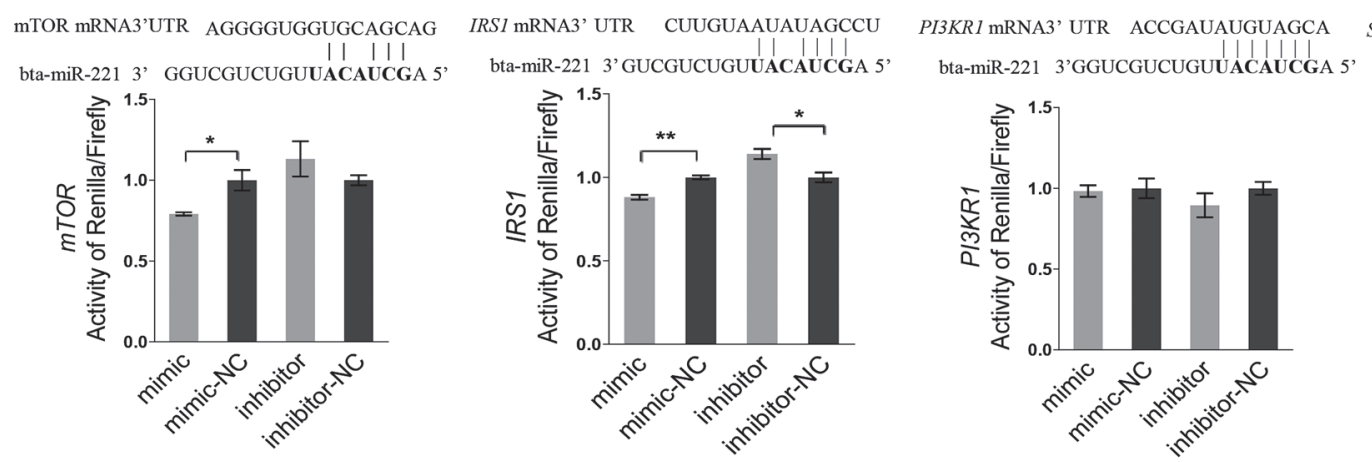

STAT3 mRNA3' UTR CGAAAGGAUGCAGCUG

bta-miR-221 3'GGUCGUCUGUUACAUCGA 5 bta-miR-221 3' GGUCGUCUGUUACAUCGA 5'

IGF1 mRNA3' UTR UAUUGUAAUGUAGCG GF1 mRNA3' UTR UAUUGUAAUGUAGCG
|||||||| $\mid l$
bta-miR-221 3' GUCGUCUGUUACAUCGA 5'

STAT5 $a$ mRNA3' UTR UGUACACAUGUAGAU

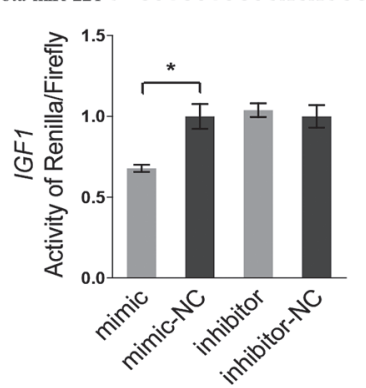
bta-miR-221 3' GGUCGUCUGUUACAUCGA 5,
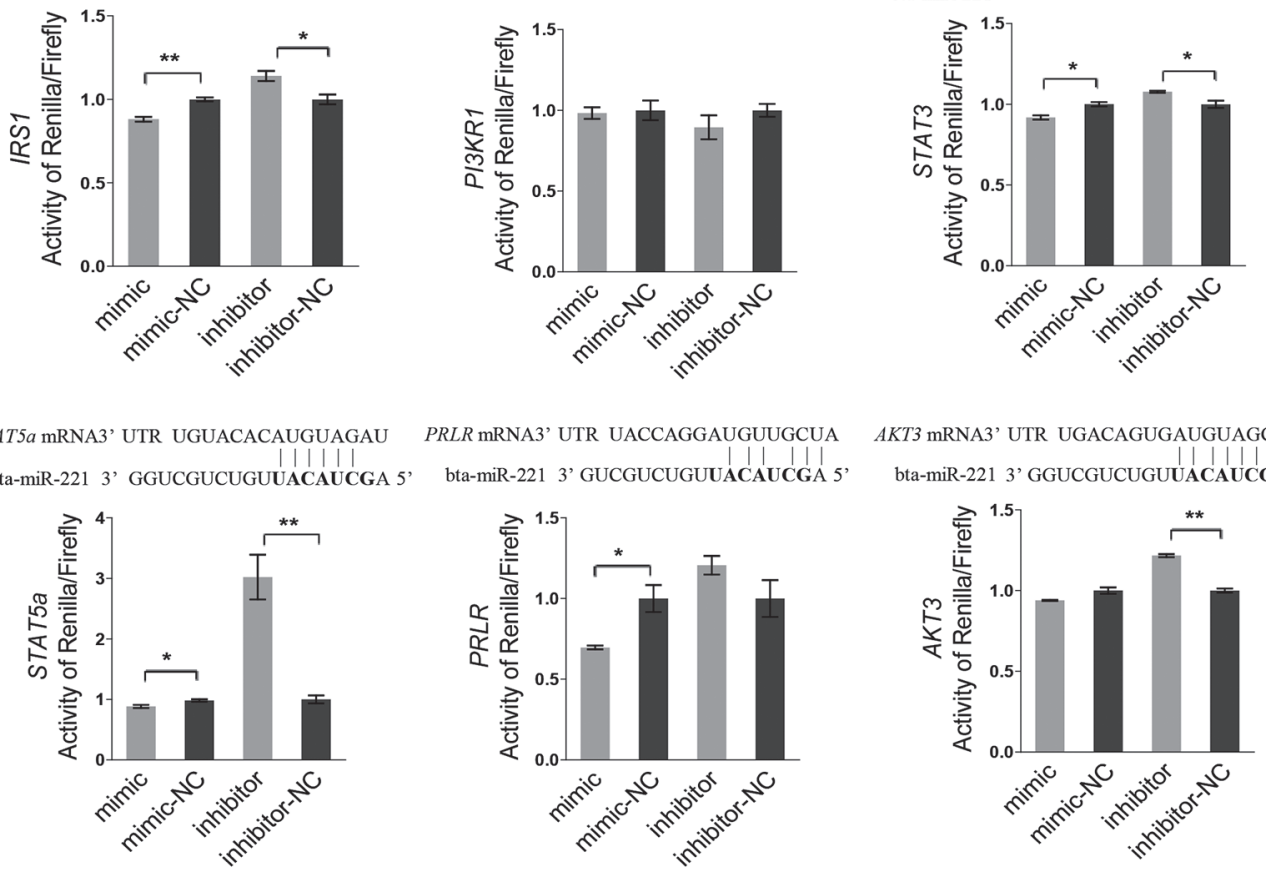

Figure 3. Dual luciferase assay to detect interactions between microRNA (miR)-221 and potential target genes. The Renilla/firefly activity was measured in HEK293T cells co-transfected with the vector constructs of the target genes and with miR-221 mimic and miR-221 inhibitor. Binding sites of the $3^{\prime}$-untranslated regions (UTR) of the candidate target genes and miR-221 are shown. Data are presented as mean \pm SEM $(\mathrm{n}=3){ }^{*} P<0.05,{ }^{* *} P<0.01$, or ${ }^{* * *} P<0.001$ : significant difference between mimic or inhibitor and respective controls (NC). 
A

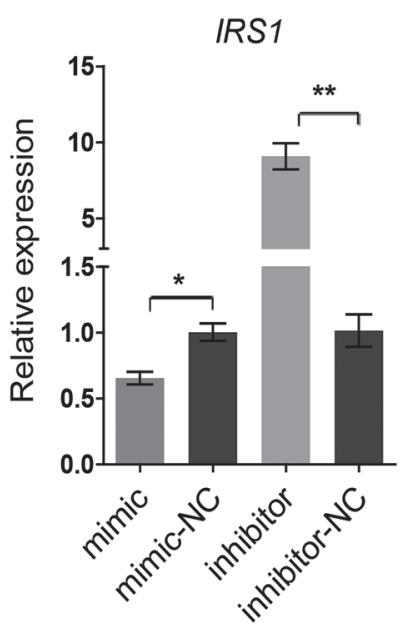

STAT5a

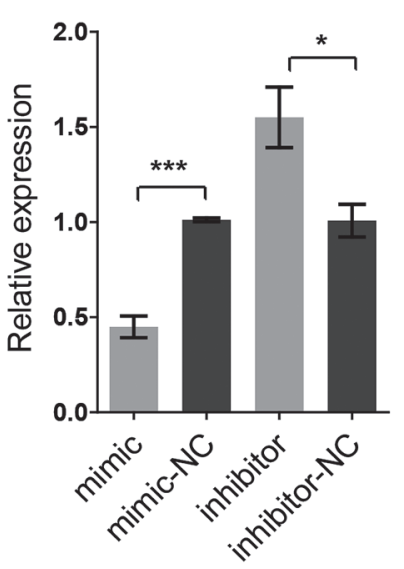

STAT3

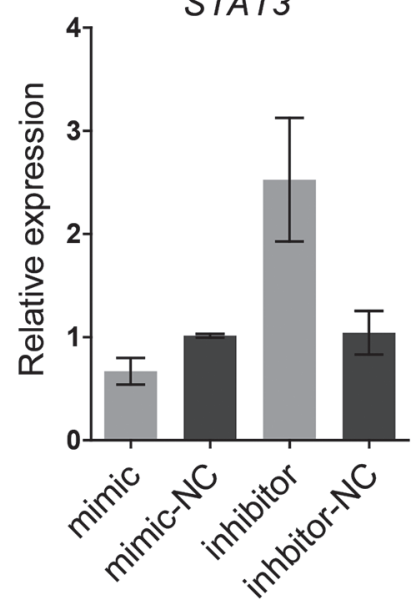

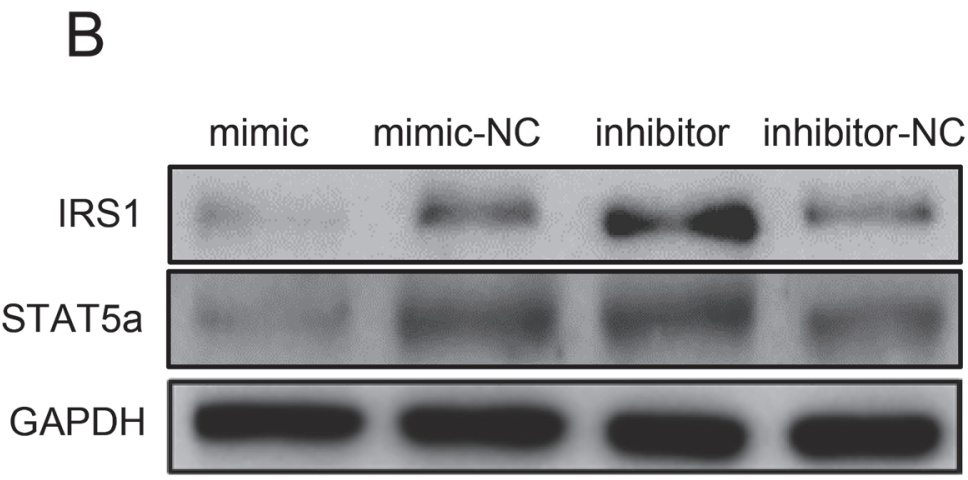

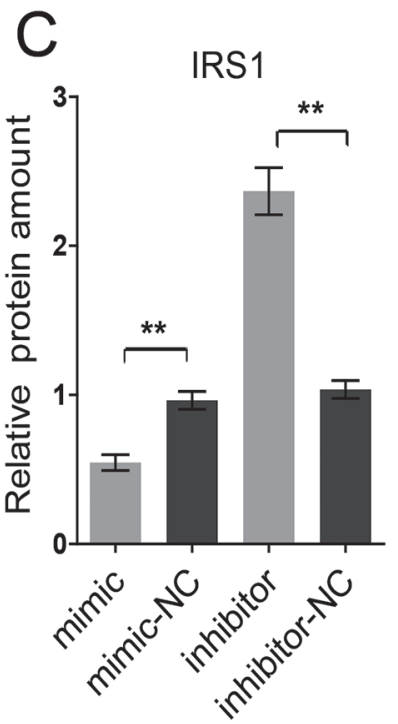

STAT5a

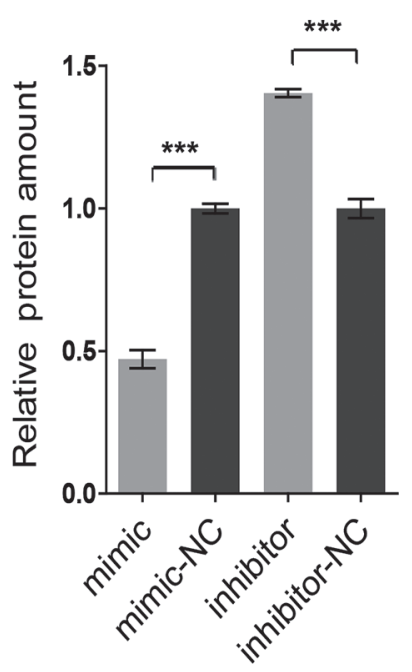

Figure 4. Expression of insulin receptor substrate 1 (IRS1) and signal transducer and activator of transcription 5a (STAT5a) at the mRNA and protein levels in bovine mammary epithelial cells transfected with microRNA (miR)-221 mimic or miR-221 inhibitor. (A) The relative expression of IRS1 and STAT5a was significantly decreased after miR-221 mimic transfection and increased after miR-221 inhibitor transfection; (B) Western blot of IRS1 and STAT5a and their negative controls using GAPDH as a reference control; (C) relative expression of IRS1 and STAT5a proteins after miR-221 mimic or miR-221 inhibitor transfections into bovine mammary epithelial cells (BMEC). Data are presented as mean \pm SEM $(\mathrm{n}=3){ }^{*} P<0.05,{ }^{* *} P<0.01$, or ${ }^{* * *} P<0.001$ : significant difference between mimic or inhibitor and respective controls (NC).

pathway). Further analysis revealed that STAT5a and IRS1 are regulated by miR-221 at both the transcriptional and translational levels. Overexpression of miR221 led to decreased expression, and its inhibition led to increased expression of STAT5a and IRS1. Interestingly, it has been found that tyrosine-phosphorylated STAT5 interacts with the PIK3R1 regulatory subunit of PI3K, a member of PI3K-Akt/mTOR, to activate the JAK-STAT pathway, which in turn promotes cell survival and proliferation (Rädler et al., 2017). Thus, the regulation of STAT5a by miR-221 sheds new light on the combined effects of both signaling pathways, JAK-STAT and PI3K-Akt/mTOR, on mammary gland development. Additionally, STAT5a can mediate a signal-transduction pathway to regulate milk protein synthesis, to regulate mammary gland epithelial cell differentiation in pregnancy, and to maintain survival of breast epithelial cells (Faraci-Orf et al., 2006; Buser et al., 2007).

Insulin has been reported to stimulate cell proliferation and the expression of milk protein genes in bovine mammary epithelial cells and in mouse mammary glands (Lanna and Bauman, 1999; Menzies et al., 2009, 2010). The IRS1 protein is a signaling adapter for insulin-like growth factor 1 receptor $(I G F 1 R)$ and insulin receptor $(I R)$, which play a central role in cell 
signaling molecule networks, including the PI3K-Akt/ mTOR signal pathway ( $\mathrm{Yu}$ and Rohan, 2000; Baserga et al., 2003; Cao et al., 2007). Interestingly, Chen et al. (1997) reported that the major insulin receptor substrate IRS-1 activates STAT5 by phosphorylation. Furthermore, IRS1 is involved in insulin-dependent activation of Akt signaling within the lactating mammary gland, although the loss of IRS1 protein has only a modest effect on normal milk synthesis (Hadsell et al., 2007). In this study, IRS1 was identified as a target of miR-221, and overexpression of miR-221 led to a decreased expression of IRS1 at both the transcriptional and translational levels. Thus, the finding that miR-221 regulates both STAT5a and IRS1 indicates a major role for miR-221 in mammary gland development.

For a deeper understanding of the subsequent effects of STAT5a and IRS1 regulation by miR-221, we analyzed the downstream genes SOCS3, AKT3, and $m$ TOR located in the JAK-STAT and PI3K-Akt/ mTOR pathways for gene expression changes. Overexpression of miR-221 led to a reduced expression of SOCS3, and inhibition of miR-221 resulted in increased expression of $S O C S 3$, which is a suppressor of cytokine signaling and a downstream gene in the JAK-STAT signaling pathway. It has been reported that the functions of JAK2-STAT5 in breast development and lactation could be modulated by the SOCS family (Huang et al., 2013; Arun et al., 2015). Huang et al. (2013) found that reduced activity of STAT5a was associated with a decreased expression of SOCS 3 and concluded that SOCS3 could be a target of STAT5a. Thus, our results on the expression analysis of these 2 genes support the findings of Huang et al. (2013) and provide an additional layer of information regarding the role of miR221 in regulating STAT5a expression. Thus, miR-221 could be involved in mammary epithelial cell proliferation by regulating the expression of STAT $5 a$, which in turn suppresses SOCS3 expression. Indeed, it has been reported that low expression of SOCS3 is required for milk synthesis and proliferation of dairy cow mammary epithelial cells in vitro (Huang et al., 2013).

Given that the PI3K-Akt-mTOR signaling pathway is activated by IRS1 (Yu and Rohan, 2000) and that IRS1 is regulated by miR-221, the downstream genes mTOR and AKT3 were evaluated for gene expression following miR-221 transfection. The expression of $A K T 3$ and mTOR was significantly reduced after transfecting miR-221 mimic into BMEC (Figure 5). Because miR-221 had no observed interaction with the 3'-UTR of AKT3 using the dual luciferase assay (Figure 3), we conclude that the effect of miR-221 on AKT3 expression is modulated through IRS1. Different knockout mice of $A K T 1,-2$, and -3 have shown that $A K T$ is necessary for STAT5 activation and mammary gland cell proliferation (Chen et al., 2010). Thus, our results provide further validation that miR-221 might regulate bovine mammary gland epithelial cell proliferation by regulating some key genes in the JAK-STAT and PI3K-AKT/mTOR signaling pathways.

\section{CONCLUSIONS}

This study is the first to illustrate the functional and regulatory mechanism of miR-221 in cultured bovine
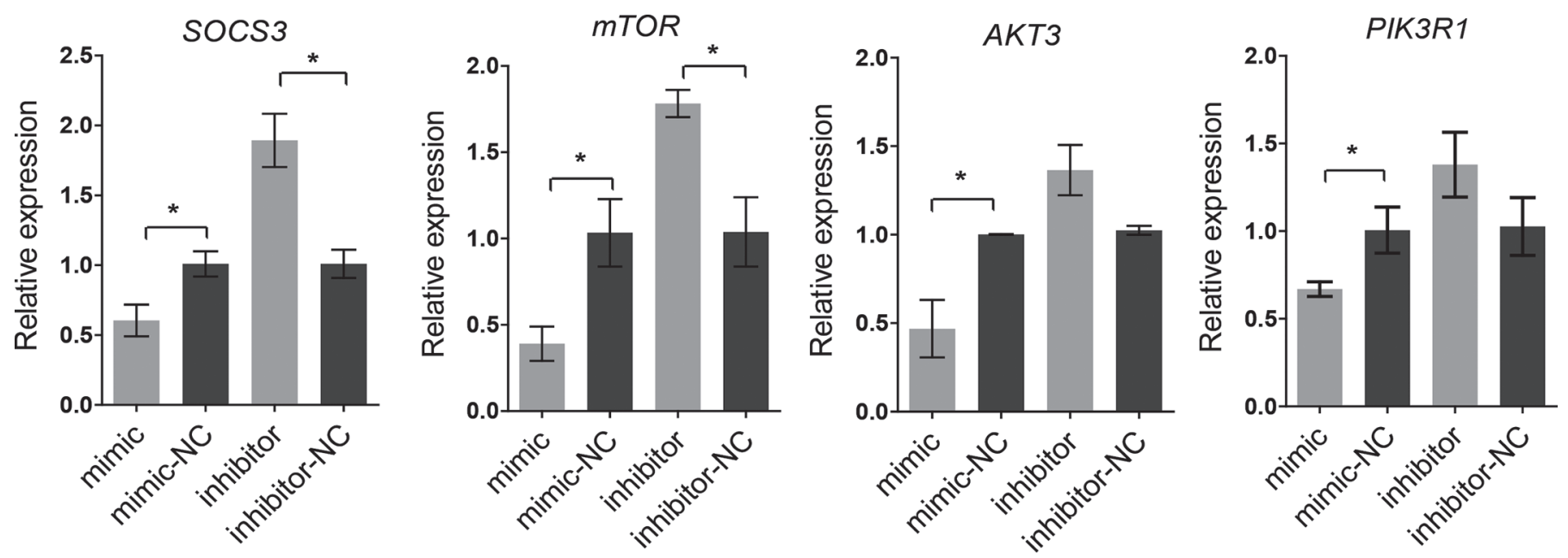

Figure 5. Relative expression of the downstream genes SOCS3, AKT3, and mTOR in the Janus kinase-signal transducer and activator of transcription (JAK-STAT) and PI3K-Akt/mammalian target of rapamycin (mTOR) signaling pathways. Expression levels of SOCS3, AKT3, and $m$ TOR were significantly decreased after microRNA $(\mathrm{miR})-221$ mimic transfection into bovine mammary epithelial cells $(P<0.05)$, and the expression of SOCS3 and $m$ TOR was significantly increased after transfection of miR-221 inhibitor $(P<0.05)$. Data are presented as mean \pm SEM $(\mathrm{n}=3) ;{ }^{*} P<0.05$ : significant difference between mimic or inhibitor and respective controls (NC). 
mammary epithelial cells. The MTT assay and flow cytometry analysis revealed that miR-221 could inhibit mammary gland epithelial cell proliferation by targeting STAT5a and IRS1, key genes in the PI3K-Akt/mTOR and JAK-STAT signaling pathways, respectively. The finding that miR-221 is involved in the regulation of these pathways would be valuable to enhance our understanding of the mechanisms of mammary gland development and milk synthesis.

\section{ACKNOWLEDGMENTS}

This research was supported by the Program for New Excellent Talents in University (NCET-13-0485), Natural Science Foundation of China (31772573), and Agricultural Science and Technology Innovation Project of Shandong Academy of Agricultural Sciences (CXGC2016B03). XW conceived the study and participated in the design of experiments and drafting of the manuscript; BLJ performed MTT, qPCR, and Western blot experiments and drafted the manuscript; XLZ and SHW constructed the vectors; LXW and HBZ performed cell culture experiments; and HK contributed to data analysis and participated in drafting the manuscript.

\section{REFERENCES}

Arun, S. J., P. C. Thomson, P. A. Sheehy, M. S. Khatkar, H. W. Raadsma, and P. Williamson. 2015. Targeted analysis reveals an important roles of JAK-STAT-SOCS genes for milk production traits in Australian dairy cattle. Front. Genet. 6:342.

Avril-Sassen, S., L. D. Goldstein, J. Stingl, C. Blenkiron, J. L. Quesne, I. Spiteri, K. Karagavriilidou, C. J. Watson, S. Tavaré, and E. A. Miska. 2009. Characterisation of microRNA expression in post-natal mouse mammary gland development. BMC Genomics 10:548.

Baserga, R., F. Peruzzi, and K. Reiss. 2003. The IGF-1 receptor in cancer biology. Int. J. Cancer 107:873-877.

Buser, A. C., E. K. Gass-Handel, S. L. Wyszomierski, W. Doppler, S. A. Leonhardt, J. Schaak, J. M. Rosen, H. Watkin, S. M. Anderson, and D. P. Edwards. 2007. Progesterone receptor repression of prolactin/signal transducer and activator of transcription 5-mediated transcription of the beta-casein gene in mammary epithelial cells. Mol. Endocrinol. 21:106-125.

Cao, Z., L. Z. Liu, A. D. Dan, J. Z. Zheng, B. Chandran, and B. H. Jiang. 2007. Insulin-like growth factor-I induces cyclooxygenase-2 expression via PI3K, MAPK and PKC signaling pathways in human ovarian cancer cells. Cell. Signal. 19:1542-1553.

Chao, C. H., C. C. Chang, M. J. Wu, H. W. Ko, D. Wang, M. C. Hung, J. Y. Yang, and C. J. Chang. 2014. MicroRNA-205 signaling regulates mammary stem cell fate and tumorigenesis. J. Clin. Invest. 124:3093-3106.

Chen, C. C., R. B. Boxer, D. B. Stairs, C. P. Portocarrero, R. H Horton, J. V. Alvarez, M. J. Birnbaum, and L. A. Chodosh. 2010. AKT is required for STAT5 activation and mammary differentiation. Breast Cancer Res. 12:R72.

Chen, J., H. B. Sadowski, R. A. Kohanski, and L. H. Wang. 1997. STAT5 is a physiological substrate of the insulin receptor. Proc. Natl. Acad. Sci. USA 94:2295-2300.

Chen, T. Y., S. H. Lee, S. S. Dhar, and M. G. Lee. 2018. Protein arginine methyltransferase 7-meidiated microRNA-221 repression maintains Oct4, Nanog, and Sox2 levels in mouse embryonic stem cells. J. Biol. Chem. 293:3925-3936.

Chu, M. Q., Y. Zhao, S. Yu, Y. N. Hao, P. F. Zhang, Y. N. Feng, H. F. Zhang, D. X. Ma, J. Liu, M. Cheng, L. Li, W. Shen, H. F. Cao, Q. Li, and L. J. Min. 2018. MicroRNA-221 may be imvolved in lipid metabolism in mammary epithelial cell. Int. J. Biochem. Cell Biol. 97:118-127.

Cui, Y., G. Riedlinger, K. Miyoshi, W. Tang, C. Li, C. X. Deng, G. W. Robinson, and L. Hennighausen. 2004. Inactivation of Stat5 in mouse mammary epithelium during pregnancy reveals distinct functions in cell proliferation, survival, and differentiation. Mol. Cell. Biol. 24:8037-8047.

Ersahin, T., N. Tuncbag, and R. Cetin-Atalay. 2015. The PI3K/AKT/ mTOR interactive pathway. Mol. Biosyst. 11:1946.

Faraci-Orf, E., C. Mcfadden, and W. F. Vogel. 2006. DDR1 signaling is essential to sustain stat5 function during lactogenesis. J. Cell. Biochem. 97:109-121.

Felli, N., L. Fontana, E. Pelosi, R. Botta, D. Bonci, F. Facchiano, F. Liuzzi, V. Lulli, O. Morsilli, and S. Santoro. 2005. MicroRNAs 221 and 222 inhibit normal erythropoiesis and erythroleukemic cell growth via kit receptor down-modulation. Proc. Natl. Acad. Sci. USA 102:18081-18086.

Furth, P. A., R. E. Nakles, S. Millman, E. S. Diaz-Cruz, and M. C. Cabrera. 2011. Signal transducer and activator of transcription 5 as a key signalling pathway in normal mammary gland developmental biology and breast cancer. Breast Cancer Res. 13:220.

Galardi, S., N. Mercatelli, E. Giorda, S. Massalini, G. V. Frajese, S. A. Ciafrè, and M. G. Farace. 2007. MiR-221 and miR-222 expression affects the proliferation potential of human prostate carcinoma cell lines by targeting p27kip1. J. Biol. Chem. 282:23716-23724.

Greene, S. B., P. H. Gunaratne, S. M. Hammond, and J. M. Rosen 2010. A putative role for microrna-205 in mammary epithelial cell progenitors. J. Cell Sci. 123:606-618.

Guan, L., X. Hu, L. Liu, Y. Xing, Z. Zhou, X. Liang, Q. Yang, S. Jin, J. Bao, H. Gao, M. Du, J. Li, and L. Zhang. 2017. Bta-miR-23a involves in adipogenesis of progenitor cells derived from fetal bovine skeletal muscle. Sci. Rep. 7:43716.

Hadsell, D. L., W. Olea, N. Lawrence, J. George, D. Torres, T. Kadowaki, and A. V. Lee. 2007. Decreased lactation capacity and altered milk composition in insulin receptor substrate null mice is associated with decreased maternal body mass and reduced insulin-dependent phosphorylation of mammary Akt. J. Endocrinol. 194:327-336.

Hennighausen, L., and G. W. Robinson. 2001. Signaling pathways in mammary gland development. Dev. Cell 1:467-475.

Howard, B., and A. Ashworth. 2006. Signalling pathways implicated in early mammary gland morphogenesis and breast cancer. PLoS Genet. 2:e112.

Howe, E. N., D. R. Cochrane, and J. K. Richer. 2012. The mir-200 and mir-221/222 microRNA families: Opposing effects on epithelial identity. J. Mammary Gland Biol. Neoplasia 17:65-77.

Huang, Y., X. J. Shen, Q. Zou, S. P. Wang, S. M. Tang, and G. Z. Zhang. 2011. Biological functions of microRNAs: A review. J. Physiol. Biochem. 67:129-139.

Huang, Y. L., F. Zhao, C. C. Luo, X. Zhang, Y. Si, Z. Sun, L. Zhang, Q. Z. Li, and X. J. Gao. 2013. Socs3-mediated blockade reveals major contribution of JAK2/STAT5 signaling pathway to lactation and proliferation of dairy cow mammary epithelial cells in vitro. Molecules 18:12987-13002.

Huynh, H. T., G. Robitaille, and J. D. Turner. 1991. Establishment of bovine mammary epithelial cells (MAC-T): An in vitro model for bovine lactation. Exp. Cell Res. 197:191-199.

Ibarra, I., Y. Erlich, S. K. Muthuswamy, R. Sachidanandam, and G. J. Hannon. 2007. A role for microRNAs in maintenance of mouse mammary epithelial progenitor cells. Genes Dev. 21:3238-3243.

Lanna, D. P. D., and D. E. Bauman. 1999. Effect of somatotropin, insulin, and glucocorticoid on lipolysis in chronic cultures of adipose tissue from lactating cows. J. Dairy Sci. 82:60-68.

Law, N. C., M. F. White, and M. E. Hunzicker-Dunn. 2016. G protein-coupled receptors (GPCRs) that signal via protein kinase A (PKA) cross-talk at insulin receptor substrate 1(IRS1) to activate 
the phosphatidylinositol 3-kinase (PI3K) AKT pathway. J. Biol. Chem. 291:27160-27169.

Li, H. M., C. M. Wang, Q. Z. Li, and X. J. Gao. 2012. Mir-15a decreases bovine mammary epithelial cell viability and lactation and regulates growth hormone receptor expression. Molecules 17:12037-12048.

Li, H. X., Z. Y. Wang, Z. Zhang, X. Zhou, X. C. Wang, Z. Y. Han, and G. L. Wang. 2010. Effects of microRNA-24 on bovine mammary epithelial cells proliferation and apoptosis at high temperature. Zhongguo Nong Ye Ke Xue 43:4732-4738.

Liu, C. G., G. A. Calin, B. Meloon, N. Gamliel, C. Sevignani, M. Ferracin, C. D. Dumitru, M. Shimizu, S. Zupo, M. Dono, H. Alder, F. Bullrich, M. Negrini, and C. M. Croce. 2004. An oligonucleotide microchip for genome-wide microrna profiling in human and mouse tissues. Proc. Natl. Acad. Sci. USA 101:9740-9744.

Liu, S., S. H. Patel, C. Ginestier, I. Ibarra, R. Martintrevino, S. Bai, S. P. Mcdermott, L. Shang, J. Ke, and S. J. Ou. 2012a. MicroRNA93 regulates proliferation and differentiation of normal and malignant breast stem cells. PLoS Genet. 8:e1002751.

Liu, X., G. W. Robinson, K. U. Wagner, L. Garrett, A. Wynshawboris, and L. Hennighausen. 1997. Stat5a is mandatory for adult mammary gland development and lactogenesis. Genes Dev. 11:179-186.

Liu, X. F., M. Li, Q. Z. Li, M. L. Li, H. L. Tong, and X. J. Gao. 2012b. Stat5a increases lactation of dairy cow mammary gland epithelial cells cultured in vitro. In Vitro Cell. Dev. Biol. Anim. 48:554-561.

Livak, K. J., and T. D. Schmittgen. 2001. Analysis of relative gene expression data using real-time quantitative PCR and the $2(\mathrm{~T})$ (-Delta Delta C) method. Methods 25:402-408.

Lv, C., F. Li, X. Li, Y. Tian, Y. Zhang, X. Sheng, Y. Song, Q. Meng, S. Yuan, L. Luan, T. Andl, X. Feng, B. Jiao, M. Xu, M. V. Plikus, X. Dai, C. Lengner, W. Cui, F. Ren, J. Shuai, S. E. Millar, and Z. Yu. 2017. MiR-31 promotes mammary stem cell expansion and breast tumorigenensis by suppressing Wnt signaling antagonists. Nat. Commun. 8:1036.

Macias, H., and L. Hinck. 2012. Mammary gland development. Wiley Interdiscip. Rev. Dev. Biol. 1:533-557.

Mapes, J., Q. Li, A. Kannan, L. Anandan, M. Laws, J. P. Lydon, I. C. Bagchi, and M. K. Bagchi. 2017. Cuzd1 is a critical mediator of the JAK/STAT5 signaling pathway that controls mammary gland development during pregnancy. PLoS Genet. 13:e1006654.

Menzies, K. K., H. J. Lee, C. Lefèvre, C. J. Ormandy, K. L. Macmillan, and K. R. Nicholas. 2010. Insulin, a key regulator of hormone responsive milk protein synthesis during lactogenesis in murine mammary explants. Funct. Integr. Genomics 10:87-95.

Menzies, K. K., C. Lefèvre, K. L. Macmillan, and K. R. Nicholas. 2009. Insulin regulates milk protein synthesis at multiple levels in the bovine mammary gland. Funct. Integr. Genomics 9:197-217.

Oka, T., M. Yoshimura, S. Lavandero, K. Wada, and Y. Ohba. 1991. Control of growth and differentiation of the mammary gland by growth factors. J. Dairy Sci. 74:2788-2800.

Phua, Y. W., A. Nguyen, D. L. Roden, B. Elsworth, N. Deng, I. Nikolic, J. Yang, A. Mcfarland, R. Russell, and W. Kaplan. 2015. MicroRNA profiling of the pubertal mouse mammary gland identifies miR-184 as a candidate breast tumour suppressor gene. Breast Cancer Res. 17:83.

Pineau, P., S. Volinia, K. McJunkin, A. Marchio, C. Battiston, B. Terris, V. Mazzaferro, S. W. Lowe, C. M. Croce, and A. Dejean. 2010.
MiR-221 overexpression contributes to liver tumorigenesis. Proc. Natl. Acad. Sci. USA 107:264-269.

Rädler, P. D., B. L. Wehde, and K. U. Wagner. 2017. Crosstalk between STAT5 activation and PI3K/AKT functions in normal and transformed mammary epithelial cells. Mol. Cell. Endocrinol. 451:31-39.

Robinson, G. W. 2004. Identification of signaling pathways in early mammary gland development by mouse genetics. Breast Cancer Res. 6:105-108.

Rong, M., G. Chen, and Y. Dang. 2013. Increased miR-221 expression in hepatocellular carcinoma tissues and its role in enhancing cell growth and inhibiting apoptosis in vitro. BMC Cancer 13:21.

Shackleton, M., F. Vaillant, K. J. Simpson, J. Stingl, G. K. Smyth, M. L. Asselinlabat, L. Wu, G. J. Lindeman, and J. E. Visvader. 2006. Generation of a functional mammary gland from a single stem cell. Nature 439:84-88.

Silveri, L., G. Tilly, J. L. Vilotte, and P. F. Le. 2006. MicroRNA involvement in mammary gland development and breast cancer. Reprod. Nutr. Dev. 46:549-556.

Sobolewska, A., M. Gajewska, J. Zarzyńska, B. Gajkowska, and T. Motyl. 2009. IGF-I, EGF, and sex steroids regulate autophagy in bovine mammary epithelial cells via the mTOR pathway. Eur. J. Cell Biol. 88:117-130.

Tanaka, T., S. Haneda, K. Imakawa, S. Sakai, and K. Nagaoka. 2009. A microRNA, miR-101a, controls mammary gland development by regulating cyclooxygenase-2 expression. Differentiation 77:181187.

Topper, Y. J., and C. S. Freeman. 1980. Multiple hormone interactions in the developmental biology of the mammary gland. Physiol. Rev. 60:1049-1106.

Ucar, A., V. Vafaizadeh, H. Jarry, J. Fiedler, P. A. Klemmt, T. Thum, B. Groner, and K. Chowdhury. 2010. MiR-212 and miR-132 are required for epithelial stromal interactions necessary for mouse mammary gland development. Nat. Genet. 42:1101-1108.

Wang, M., S. Moisá, M. J. Khan, J. Wang, D. Bu, and J. J. Loor. 2012. MicroRNA expression patterns in the bovine mammary gland are affected by stage of lactation. J. Dairy Sci. 95:6529-6535.

Wang, X., L. Zhang, J. Jin, A. Xia, C. Wang, Y. Cui, B. Qu, Q. Li, and C. Sheng. 2018. Comparative transcriptome analysis to investigate the potential role of miRNAs in milk protein/fat quality. Sci. Rep. 8:6250.

Watson, C. J., and T. G. Burdon. 1996. Prolactin signal transduction mechanisms in the mammary gland: The role of the JAK/STAT pathway. Rev. Reprod. 1:1-5.

Wei, C., Q. Li, F. Li, and D. Wei. 2011. Mir-126-3p regulates progesterone receptors and involves development and lactation of mouse mammary gland. Mol. Cell. Biochem. 355:17-25.

Wiseman, B. S., and Z. Werb. 2002. Stromal effects on mammary gland development and breast cancer. Science 296:1046-1049.

Yamaji, D., R. Na, Y. Feuermann, S. Pechhold, W. Chen, G. W. Robinson, and L. Hennighausen. 2009. Development of mammary luminal progenitor cells is controlled by the transcription factor STAT5A. Genes Dev. 23:2382-2387.

Yu, H., and T. Rohan. 2000. Role of the insulin-like growth factor family in cancer development and progression. J. Natl. Cancer Inst. 92:1472-1489. 